\title{
Vivência nas ruas, dependência de drogas e projeto de vida: um relato de experiência no CAPS-ad
}

\section{Homeless, drug addiction and project for life: an experience report in CAPS-ad Vida en la calle, dependencia química y proyecto de vida: un estudio de caso en el CAPS ad}

\author{
Célia Regina Pessanha Mendes \\ CAPS ad Ilha, Florianópolis \\ João FillipeHorr \\ Universidade Federal de Santa Catarina
}

\begin{abstract}
Resumo
A vulnerabilidade psicossocial às quais estão submetidos os dependentes de álcool e outras drogas são questões recorrentes nos CAPS ad. Sendo assim, é necessário discutir a atenção psicossocial aos sujeitos em situação de rua. Este relato de experiência tem por objetivo descrever uma intervenção no CAPS ad Continente em Florianópolis e a construção do projeto terapêutico singular no processo de reabilitação psicossocial de um usuário morador de rua com dependência de álcool.

Palavras-chave: CAPS ad; Dependência química; Vulnerabilidade psicossocial; Morador de rua; Saúde mental; Atenção psicossocial.
\end{abstract}

\begin{abstract}
Psychosocial vulnerability that afflicts the dependent users of alcohol and other drugs are recurring issues in CAPSad. Therefore, it is necessary to discuss the psychosocial care of the homeless. This experience report illustrates an intervention in CAPS-ad "Continente" in Florianópolis and a construction of the singular therapeutic project in the psychosocial rehabilitation of a homeless patients with alcohol dependence.

Key-words: CAPS ad; Alcohol and drug dependency; Psychosocial vulnerability; Homeless; Mental health; Psychosocial care.
\end{abstract}

\begin{abstract}
Resumen
La vulnerabilidade psicosocial que afecta el usuários dependientes de alcohol y otras drogas son temas recorrentes en el CAPS ad. Por lo tanto, es necessário analizar la atención psicosocial de los sujetos que viven en las calles. Este estudio de caso ilustra una intervención en el CAPS ad Continente en Florianópolis y la construcción de un projecto terapêutico singular de rehabilitación psicosocial de un usuário, que vive en la calle, con dependência de alcohol. Palabras-clave: CAPS ad; Dependencia química; Vulnerabilidad psicosocial; Personas sinhogar; Salud mental; Atención psicosocial.
\end{abstract}

\section{Introdução}

A questão do uso abusivo de substâncias psicoativas é um dos graves problemas na atualidade e tem reflexos importantes na saúde pública. Segundo levantamentos da Organização Mundial da Saúde (OMS, 2001) cerca de $10 \%$ das populações urbanas fazem uso abusivo de substâncias psicoativas, em variação de gênero, classe e etnia.

O Relatório Brasileiro sobre drogas (2009) aponta que, de 2001 para 2005, houve aumento nas estimativas de uso do álcool, tabaco, maconha, solventes, benzodiazepínicos, cocaína, estimulantes, barbitúricos, esteroides, alucinógenos e craque Nesse período a estimativa de dependentes de álcool passou de $11,2 \%$ e $12,3 \%$; e a de tabaco de $9,0 \%$ e 10,1\%. Exceto álcool e tabaco, as drogas com maior dependência são: maconha $(1,0 \%$ e $1,2 \%)$, benzodiazepínicos $(1,1 \%$ e $0,5 \%)$, solventes $(0,8 \%$ e $0,2 \%)$ e estimulantes $(0,4 \%$ e $0,2 \%)$. Ainda segundo esse estudo o gênero masculino apresenta maior uso na vida e maior dependência de álcool do que o gênero feminino, em todas as faixas etárias. A faixa etária que apresenta a maior dependência é a de 18 a 24 anos, seguida da de 25 a 34 anos. Essas observações valem para ambos os anos.

Os dados referem-se ao I e ao II Levantamento Domiciliar sobre o Uso de Drogas Psicotrópicas no Brasil, realizados pela Secretaria Nacional de Políticas sobre Drogas (SENAD) em convênio com a Universidade Federal de São Paulo, Departamento de Psicobiologia, Centro Brasileiro de Informações sobre Drogas Psicotrópicas - CEBRID - nos anos de 2001 e 2005, respectivamente.

Segundo a Classificação Internacional de Doenças (CID-10) publicada pela Organização Mundial de Saúde (OMS) a dependência de drogas é definida como um conjunto de fenômenos comportamentais, cognitivos e fisiológicos que se desenvolvem após repetido consumo de uma substância psicoativa, tipicamente associado ao desejo poderoso de tomar a droga, à dificuldade de controlar o consumo, à utilização persistente apesar das suas consequências nefastas, a uma maior prioridade dada ao uso da droga 
em detrimento de outras atividades e obrigações, a um aumento da tolerância pela droga e por vezes, a um estado de abstinência física.

Para Carlini, Nogueira, Lanferini, Ali \& Martinelli (1998) o crescimento da população de rua veio se acentuando desde os períodos de recessão econômica, quanti e qualitativamente, exigindo articulação de diversos setores como saúde, assistência social, habitação e segurança pública. A população em situação de rua não é incluída nos censos demográficos brasileiros, e de outros países, fundamentalmente porque a coleta de dados dos censos é de base domiciliar.

Uma pesquisa nacional, realizada em 2008, a pedido do Ministério do Desenvolvimento Social e Combate à Fome (MDS), traçou um perfil da população em situação de rua. De acordo com o estudo, realizado em 71 municípios nas instituições e na rua, a população em situação de rua é predominantemente masculina ( $82 \%$ ); mais da metade $(53 \%)$ possui entre 25 e 44 anos e os níveis de renda são baixos: 52,6\% recebem entre $\mathrm{R} \$ 20,00$ e $\mathrm{R} \$ 80,00$ por semana. Entre as principais razões da ida para a rua são o alcoolismo ou o uso de drogas $(35,5 \%)$; o desemprego $(29,8 \%)$ e desavenças com pai, mãe ou irmãos $(29,1 \%)$. Ainda segundo a pesquisa, a população em situação de rua é composta, em grande parte, por trabalhadores: $70,9 \%$ exercem alguma atividade remunerada como catador de materiais recicláveis, flanelinha, construção civil, limpeza e carregador ou estivador. Apenas $15,7 \%$ das pessoas pedem dinheiro como principal meio para a sobrevivência.

A dependência de álcool e outras drogas levam à fragilidade nos laços familiares e sociais e a dificuldade em manter atividades laborais. A consequência é uma população que lida com condições precárias de vida e acaba recorrendo às ruas como única opção de sobrevivência e de moradia. Devido ao alto grau de vulnerabilidade psicossocial as quais estes sujeitos estão submetidos, encontramos na rotina dos serviços de saúde demandas de cuidados físicos e psicológicos recorrentes devido à abstinência pelo uso de álcool e/ ou outras drogas. A questão do acesso é um desafio na atenção desse público, já que muitas vezes a população em situação de rua não acessa ou acessam precariamente.

Segundo o Ministério da Saúde, o baixo índice adesão aos serviços da rede pública, principalmente pela população usuária de álcool e outras drogas em situação de extrema vulnerabilidade e riscos, justifica a implantação de intervenções mais efetivas e integradas in loco (Brasil, 2010).

\section{A atenção psicossocial e o CAPS ad}

A partir da Lei 10.216/2001, a Reforma Psiquiátrica se consolida como política oficial do governo federal, e passa a reger as ações na área de saúde mental. Os centros de Atenção Psicossocial ou os CAPS têm um papel central na articulação e construção dessa rede de serviços assistenciais. O reconhecimento da importância da intersetorialidade no campo da saúde mental se fortalece a partir do redirecionamento do modelo de atenção, estando presente nas discussões, reflexões e ações na área de saúde mental, no qual os diferentes setores são convocados a contribuir em respostas as complexas demandas da área.

Historicamente os serviços oferecidos na área de álcool e drogas têm características asilares e propõem a abstinência como uma condição para o tratamento. São formadas por instituições que se denominam "Comunidades Terapêuticas" e que têm como um dos pilares o tratamento por meio do trabalho (laborterapia). Em geral preconizam um tempo de internação longo de nove à doze meses.

A Reforma Psiquiátrica que no Brasil foi um processo que teve início com o Movimento da Reforma Sanitária (Sonia Fleury \& Colaboradores) e para Amarante (1990) esse processo indica algo em permanente movimento, que não tem um fim pré-determinado, nem um objetivo último ou ótimo. Aponta para a constante inovação de atores, conceitos e princípios que marcam a evolução da história. Segundo Amarante (1990) as transformações na Saúde Mental e a atenção psicossocial podem ser entendidas em suas quatro dimensões:

- No campo epistemológico ou teórico, conceitual provoca uma revolução na construção de saberes que questionam ao paradigma saúde-doença e coloca o sujeito como o centro da cena;

- No campo técnico-assistencial com a construção de uma rede serviços que enfatiza a produção de saúde como produção de subjetividades, ao colocar a doença entre parênteses e propiciar o contato com o sujeito, resgatando a sua cidadania;

- No campo jurídico-político destacam-se as transformações quanto ao modelo de atenção à saúde mental, que passa a ser territorial e aberto, em contraposição ao modelo manicomial;

- No campo sociocultural tem-se construído uma série de práticas sociais visando transformar o imaginário social relacionado à doença mental e a anormalidade e a loucura, até chegar ao conceito existência - sofrimento, almejando aumentar a contratualidade social do sujeito

Os Centros de Atenção Psicossocial para tratamento de pessoas dependentes de álcool e outras drogas ou os CAPS ad fazem, parte da rede de serviços de saúde mental do SUS, tendo como horizonte os princípios da Reforma Psiquiátrica. A proposta do CAPS ad tem como base a atenção psicossocial e deve levar em conta a singularidade do sujeito em suas 
particularidades e isso inclui a sua vulnerabilidade psicológica, ou seja, a sua capacidade de lidar com as situações e fatores estressantes na vida. Além disso, a clínica psicossocial deve ultrapassar o curativo em direção à transformação política e cultural dos estigmas vivenciados pelos dependentes de álcool e outras drogas (Costa-Rosa, Luzio\&Yasui, 2003).

A redução de danos (RD) foi adotada como estratégia de saúde pública pela primeira vez no Brasil no município de Santos-SP no ano de 1989, quando altos índices de transmissão de HIV estavam relacionados ao uso indevido de drogas injetáveis (Mesquita, 1991). Proposta inicialmente como uma estratégia de prevenção ao HIV entre usuários de drogas injetáveis - Programa de troca de Seringas (Ptss) - a redução de danos foi ao longo dos anos se tornando uma estratégia de produção de saúde alternativa às estratégias pautadas na lógica da abstinência, incluindo a diversidade de demandas e ampliando as ofertas em saúde para a população de usuários de drogas.

A abordagem de redução de danos contribui com 'um novo olhar' sobre a prática de saúde, atentando para a consideração e valorização da independência dos sujeitos, sua cultura e suas práticas. Ao abandonar o modelo biomédico de doutrinação que qualifica comportamentos a partir de uma perspectiva bipolar de indivíduos ou comportamentos 'sãos' e 'nãosãos', considera a multiplicidade de estratégias e procura criar escalas de risco 'guias' para a orientação coletiva e/o individual. Dessa forma, é um conceito que tem uso ampliado para além da área de 'drogas', sendo utilizado em outras áreas da Saúde, como a reprodutiva (Figueiredo, 1999; Ayres, 2002).

O CAPS ad tem como proposta uma clínica embasada no compromisso ético e político dos princípios da Reforma Psiquiátrica e no acolhimento proposto pela Redução de Danos em defesa da liberdade e vida do usuário (Brasil, 2003). Isso coloca grandes desafios aos profissionais destes serviços, na construção de estratégias terapêuticas capazes de conciliar a singularidade dos usuários e o impacto coletivo das intervenções. Considerando esta reflexão sobre o papel do CAPS ad e os desafios dos profissionais, propomos essa discussão a partir de um relato de experiência. $\mathrm{O}$ que exige repensar nossas práticas e estratégias terapêuticas intra e inter institucionais na construção de vínculos com os outros serviços assistenciais da rede.

Pretendemos assim, situar o leitor no contexto da instituição, para melhor compreender o processo de intervenção desenvolvido.

\section{O CAPS ad e a construção do projeto terapêutico de um usuário morador de rua}

O CAPS ad Continente em Florianópolis foi inaugurado em 2005, inicialmente voltado para atender crianças e adolescentes que possuíam problemas relacionados ao álcool e outras drogas. A partir de 2006, reorientou sua atenção para pessoas adultas, percebendo a grande demanda dessa população para o serviço. Conforme preconizado pelo Ministério da Saúde, o CAPS ad deve oferecer atendimento diário aos pacientes que fazem uso prejudicial de álcool e outras drogas, integrando os serviços comunitários como programa de saúde da família, e permitindo o planejamento terapêutico dentro das necessidades de cada usuário do serviço. Está localizado na Rua José Cândido Silva, número 125 no bairro do Estreito em Florianópolis e é um serviço de referência para os moradores do Continente e da região do Centro no Município de Florianópolis. Funciona das 8:00 às 18:00 horas, de segunda a sexta-feira e oferece acolhimento diário pelos profissionais do serviço, para todas as pessoas que buscam atendimento relacionado ao não à dependência química.

A equipe é multiprofissional e é composta por um médico clínico e dois psiquiatras, três psicólogos, um assistente social, um enfermeiro e dois técnicos de enfermagem, um farmacêutico e pelos quatro redutores de danos que atuam também na comunidade. São desenvolvidas atividades diárias de acordo com as propostas da equipe e o processo de trabalho desenvolvido por cada profissional como atendimento individual, atendimento em grupos, oficinas terapêuticas, atendimento aos familiares, reuniões semanais com as equipes de referência e os usuários, assembleia e visitas domiciliares. Além disso, possui alguns leitos de observação e procura oferecer condições para a desintoxicação ambulatorial de alguns casos menos graves que chegam ao serviço, caso estejam intoxicados ou com quadros de abstinência.

O CAPS ad descrito é referência do Município para o atendimento aos usuários moradores de rua. Devido à vulnerabilidade desses usuários e as dificuldades em realizar o tratamento enquanto expostos aos riscos nas ruas, foi construída uma parceria entre as Secretarias da Saúde e da Assistência Social. Uma pesquisa interna sobre o perfil dos usuários atendidos nos revelou que cerca de $20 \%$ eram moradores de rua, demonstrando a necessidade do serviço em aperfeiçoar a atenção a este público específico.

A Assistência Social do Município é também responsável pela porta de entrada do morador de rua, por meio de um serviço denominado " abordagem de rua”. Este serviço realiza, após uma denúncia, busca ativa e abordagem desse morador, fazendo uma tentativa para convencê-lo a aceitar abrigo. Na grande maioria dos casos, existe dependência de álcool ou outras drogas, sendo necessário encaminhá-lo para tratamento no CAPS ad. Após avaliação no CAPS ele passa a residir na Casa de Apoio Social, uma casa de passagem que serve como um dispositivo de alta complexidade da Secretaria de Assistência Social. 
A responsabilidade do caso atravessa as instituições, necessitando de uma interlocução constante entre o CAPS ad e outros dispositivos assistenciais, especialmente com a equipe técnica da Casa de Apoio. Para isso existe uma reunião semanal entre os técnicos do CAPS ad e a equipe da Casa de Apoio, na qual são construídos, em conjunto, os projetos terapêuticos individuais desses usuários.

O caso que pretendemos descrever é de um usuário morador de rua que residiu na Casa de Apoio Social e que realizou acompanhamento no CAPS ad por cerca de 1 ano. As peculiaridades se dão não apenas pela questão da articulação intersetorial, mas também pelas intervenções realizadas neste contexto.

Como suporte teórico, recorremos aos referencias teóricos da reforma psiquiátrica e da atenção psicossocial proposta por Amarante (1999) e a idéia de reabilitação psicossocial de Saraceno (1996), que objetiva uma reconstrução do exercício da cidadania e da contratualidade social.

A Gestalt terapia foi também escolhida como proposta de intervenção na clínica. Trata-se de uma psicoterapia de base fenomenológico-existencial, que objetiva promover o processo de crescimento e desenvolver o potencial humano na tentativa de ampliar este potencial, integrando as partes conhecidas e desconhecidas, partes que aceitamos e negamos em nós mesmos. "Nós fazemos isso apoiando os interesses, desejos, e necessidades genuínas do indivíduo". (Perls, 1977, p.19).

Para Müller-Granzotto\& Müller-Granzotto (2013), “"em cada experiência de contato estabelecida em regime clínico (ampliado), o que importa ao clínico é, em tese, deixar-se arrebatar por aquilo que, no campo clínico, emerge como figura. Importa a ele, por conseguinte, deixar-se desviar (clinamen), para assim, pelo inédito que possa lhe haver surgido, provocar outros desvios (parênklisis), dessa vez no discurso, na ação e nas identificações escolhidas pelo consulente."

Tratando-se especificamente do caso em questão podemos pensar que $\mathrm{P}$, se apresenta como um dependente de álcool, sendo esse um ajustamento predominante possível para ele na sua relação com o mundo. Sendo assim, essa é a forma com que ele responde ao mal estar ou angústia provocada pela demanda social ou pelo "Outro Capitalista". Ele foge da demanda se alienando no álcool. MullerGranzotto\& Muller -Granzotto chamam esse ajustamento de banal e nos explicam da seguinte forma:

(...)nãotentam responder( comonas psicoses), menos ainda manipular (como nas neuroses). Também não procuram pedir ajuda (como no sofrimento ético político e antropológico). Eles simplesmente "substituem" a awareness pelo consumo supérfluo e inconseqüente, como se nesse tipo de consumo estivessem desincumbidos de sentir (awareness sensorial), desejar (awareness deliberada) e assumir identidades sociais (awareness reflexiva). Parecem antes desertores da própria condição se sujeitos (de Ato). (...) Trata-se de sujeitos que, diante desse outro muito poderoso, que é o outro capitalista, abrem mão de seus excitamentos e de suas autonomias criativas, mas nem por isso submetem a ele, elegendo a banalização das demandas como forma de resistência.

\section{Relato do Caso:}

P. é do sexo masculino, branco, nasceu em 1952 e atualmente tem 62anos, é viúvo, natural do Rio Grande do Sul.

Foi trazido para tratamento no CAPS ad no mês de junho de 2010. Chegou com a Abordagem de Rua e foi abrigado na Casa de Apoio Social.

\section{Acolhimento Inicial no CAPS ad}

P. chegou ao CAPS ad em graves e precárias condições de saúde física e mental. Confuso, desorientado, desidratado e desnutrido, fácies edemaciada,ictérico e bastante emagrecido. Não se alimentava há vários dias e precisava ser carregado, pois também não conseguia mais andar. Apresentava sinais de abstinência do álcool com graves tremores nas mãos, sudorese e taquicardia. P. é alcoolista de longa data e fazia uso diário de 3 litros de cachaça por dia. Foi necessário permanecer em observação clínica e iniciar medicação para aliviar os sintomas da abstinência com hidratação e suporte vitamínico.

A Casa de Apoio oferecia esse suporte aos pacientes em "desintoxicação", apesar de não contar com estrutura de enfermagem, os monitores eram responsáveis por administrar a medicação desses pacientes durante o período da noite e tinham suporte clínico também do posto de saúde nos dias em que não vinham ao CAPS ad.

$\mathrm{O}$ projeto terapêutico inicial de P. era o mesmo para todos os usuários albergados na Casa de Apoio que eram trazidos de carro, três vezes na semana para participar durante o dia todo das atividades no CAPS ad.

Todos os moradores de rua albergados na Casa de Apoio não podiam sair sem permissão da equipe de Assistentes Sociais da Casa. O CAPS ad como um serviço aberto não tinha essa mesma regra, apesar de orientar os pacientes quanto ao risco de perderem a vaga na Casa de Apoio, caso a regra fosse descumprida durante o período permanecido no CAPS ad. Essa regra foi um dos pontos trabalhados pela equipe do CAPS ad com a equipe da Casa de Apoio no processo de construção dos projetos terapêuticos individuais dos usuários.

\section{A História de P.e o processo de auto abandono}

Quando passou o período da abstinência do álcool e ,após os cuidados médicos iniciais, P. estava 
fisicamente mais forte e lúcido. Conta que há cinco anos vivia nas ruas de Florianópolis e que antes havia morado em várias cidades, sempre como andarilho, algumas vezes morava nas ruas e outras vezes, conseguia algum abrigo. Relata que fazia questão de "ser invisível" e que podia fazer isso como morador de rua. Aos poucos começa a trazer nos grupos e também nos atendimentos individuais a sua história de vida e tenta assim se reconstruir enquanto sujeito.

Relata que trabalhou como jornalista e que escrevia para jornais em São Paulo, cidade onde morava com a esposa. Diz que não tiveram filhos e que viveram juntos por 15 anos. Afirma que ela havia sido o maior amor de sua vida. Era filho único de mãe solteira e foi criado pela mãe e pela avó materna. $\mathrm{O}$ pai "desapareceu" de sua vida quando tinha quatro anos e diz que não tem lembrança alguma dele. Relata que sempre teve de tudo o que queria e que a mãe e a avó faziam todas as suas vontades. Conta que o avô e os tios maternos eram militares e que ele sempre foi a "ovelha negra" da família "porque não queria seguir o mesmo caminho". Relata com entusiasmo como participou da resistência ao golpe militar quando estudante em 64. Estudou nos melhores colégios particulares em Porto Alegre e sempre gostou de ler e escrever, decidindo então se tornar jornalista, porém diz que nunca precisou fazer curso superior na área.

Teve contato com as drogas e o álcool ainda na adolescência, mas afirma que nunca foi "dependente". Diz que costumava usar com freqüência, principalmente o álcool, pois era tímido para as conquistas amorosas. Conta que conheceu sua esposa pouco depois do falecimento da mãe e da avó, que ocorreu no mesmo ano. Diz que "a paixão foi tão grande" que logo foram morar juntos. Viveram felizes por 15 anos e diz que se completavam, pois ela trabalhava como contadora e era mais "pé no chão" que ele. Conta que nunca foi muito responsável com as contas, que era do tipo "sonhador" e gostava de ser conhecido como "poeta".

Fala com muita emoção sobre o falecimento de sua esposa em um acidente automobilístico na "via Dutra", no qual ele dirigia o carro. Afirma não ser o culpado pelo acidente porque um caminhão atravessou a pista, atingindo o lado do carro onde ela estava. Porém fugiu de São Paulo logo após o enterro, por não conseguir encarar os amigos e os familiares dela. Diz que sentia culpa "por ainda estar vivo".

Passou a viver como andarilho por várias cidades, intensificando assim o uso do álcool. Inicialmente escrevia pequenos livretos de poemas que vendia nos bares noturnos e assim conseguia sobreviver e pagar um quarto para morar, mas com o tempo a dependência do álcool se agravou e não conseguia mais escrever suas poesias e nem pagar um aluguel, passando a viver nas ruas. Em algumas cidades, conseguia abrigo e parava algum tempo com a bebida, passando novamente a escrever inclusive para jornais locais onde conseguia até ter uma projeção como poeta e escritor, mas logo vinham as recaídas no álcool e acabava mudando novamente de cidade. Relata que estava há cinco anos morando nas ruas em Florianópolis, antes de ter sido recolhido pela Assistência Social, entregue a dependência do álcool. Este ponto é importante para compreender a circularidade entre as vivências na rua e a longa história da dependência, que impedem o sujeito de viver novos papéis. A diversidade de fatores a serem trabalhados na reabilitação psicossocial corresponde à variedade de aspectos existentes na vida de uma pessoa. Assim, o profissional de Saúde Mental pode, através de um processo de comunicação, de escuta, de acolhimento e de atividades prático-criativas, junto com o portador de sofrimento mental, agir como facilitador na construção de novas configurações mentais, nas quais o sistema de relações que compõe a vida dessa pessoa possa se auto-reorganizar, desse modo, se estabilizando em um novo padrão de relações.

\section{Acompanhamento no CAPSad e processo de intervenção:}

P. gostava de ficar isolado do grupo, preferia ler na biblioteca do CAPS ad. Gostava de participar dos grupos temáticos de reflexão. Sentia-se mais atraído pelos temas polêmicos e de posicionamento político. Falava pouco de si mesmo nos grupos. Nesse período começou a escrever e fez um primeiro livro de poemas, intitulado: "Saindo do Poço".

Este primeiro livro tornou possível a P. conquistar maior autonomia na Casa de Apoio Social, recebendo autorização para vir sozinho a pé ao CAPS ad, ampliando sua contratualidade social (Saraceno, 2001). Passou a buscar patrocínio para o livro e a fazer amizades com os comerciantes da redondeza.

Certo dia comentou da possibilidade de escrever sobre o cotidiano do CAPS ad e surgiu a idéia de fazer um jornal. Essa idéia foi levada por ele para a assembléia de usuários do CAPS ad e se tornou uma nova oficina. Também foi votado na assembléia o nome do jornal e nasceu o "Nossa Voz". Nesse momento a Oficina de Jornal passa a ser o seu projeto terapêutico. Assim ao identificar em P. o desejo de escrever sobre o cotidiano do CAPS ad, temos a chance de encorajá-lo a tornar concreto esse projeto, com a criação da oficina do Jornal.

A oficina acontecia semanalmente para preparar os temas que seriam abordados no jornal e pouco a pouco outros usuários se juntaram a nós. $\mathrm{P}$. era o redator e preparava as matérias na Casa de Apoio, tendo aí mais uma conquista, pois conseguiu permissão para usar o computador da Casa por algumas horas no dia. Alguns usuários eram os repórteres, outros poetas e fotógrafos. A equipe técnica ficou responsável por articular a construção do jornal, através da diagramação e da impressão do jornal. 
O primeiro número saiu em janeiro de 2011 e teve como tema o próprio CAPS ad Continente e sua história. O jornal como dispositivo terapêutico foi pensado no sentido de resgatar a retomada dos projetos de vida de P., enquanto escritor, poeta e jornalista.

Para o segundo número do jornal P. preparou um artigo sobre a Casa de Apoio e a Abordagem de Rua e convidou a equipe para visitar a "sua casa" e conhecer o seu quarto, os amigos da casa e o computador onde escrevia suas histórias.

Esse número do jornal nos deu oportunidade de realizar visitas às outras instituições assistenciais para algumas entrevistas. Assim, P. pode se reencontrar com as pessoas que o tiraram da rua, a equipe da Abordagem de Rua e do Serviço Social. Foi entrevistar e fotografar todos para o jornal. Esta situação também promoveu importante troca e construção de vínculos com a equipe do CAPS ad e possibilitou maior aproximação com as outras instituições envolvidas no trabalho intersetorial conosco.

Por ocasião do carnaval, P. comentou que havia encontrado um amigo antigo do tempo da rua e que este o havia convidado para fazer a música do bloco de carnaval, falou com pesar sobre a impossibilidade de participar do carnaval por causa do risco da recaída. P. diz que sempre gostou muito de participar da festa e dos blocos de carnaval. Nesse momento sugeri a ele que fizesse a música para o bloco de carnaval do CAPS ad o que ele aceitou de pronto e logo contagiou a todos com a marchinha dos "Ex-pirados". Ensaiamos a música e por ocasião do carnaval saímos numa grande festa pelas redondezas do CAPS ad. P. comentou emocionado o fato de um grupo de crianças e professoras de uma pré-escola terem dançado junto com o bloco quando este passou em frente à escola. É claro que esse foi o tema escolhido para o terceiro número do jornal.

O quarto número teve uma participação mais efetiva de outros usuários e falamos sobre uma visita ao CAPS II Ponta do Coral. Por ocasião da festa junina P. conheceu e começou a se relacionar com uma usuária deste CAPS e que também começou a participar da oficina de jornal do CAPS ad. Essa relação resultouem uma maior liberdade e autonomia de $\mathrm{P}$. em relação à Casa de Apoio pois podia dormir fora da casa e até passar os finais de semana com a namorada.

Por ocasião do Congresso Catarinense de Saúde Mental os usuários do CAPS ad e a equipe do "Nossa Voz" participam ativamente.O quinto e último número do jornal traz uma entrevista e fotos com Paulo Amarante feitos pela equipe do "Nossa Voz" durante o evento. Neste número também temos a matéria sobre o lançamento de outro livro de P., que aconteceu na sede da Secretaria de Assistência Social, quando foi homenageado pelo Secretário de Assistência Social do Município, sendo bastante aplaudido e elogiado por todos. Nessa ocasião recebeu também um convite para uma entrevista numa TV local, em que falou um pouco de sua história e divulgou o seu último livro.

Observa-se aí uma mudança de P. e a conquista de maior autonomia em propor questões pertinentes, especialmente utilizando o "Nossa Voz" como instrumento de informação. Por suas próprias "características jornalísticas", P. foi capaz de exercer um papel mais ativo nas questões políticas do município naquele período, sendo convidado a participar de reuniões e discussões sobre a política pública do município em relação aos moradores de rua.

Após a divulgação do livro, P. dizia estar pronto para deixar a Casa de Apoio; apesar de não ter direito a nenhum benefício financeiro. Falava em sair da Casa de Apoio porque já havia tido "regalias" e ficado tempo demais. Decidiu tentar vender o seu livro para pagar um quarto e teve uma proposta de trabalhar na gráfica de um amigo, o mesmo que fazia as impressões do jornal. P. conseguiu ficar sem beber até o carnaval, quando recaiu no álcool e pouco depois foi despejado, pois não conseguira manter o emprego passando a morar novamente na rua.

$\mathrm{Na}$ época não podia mais voltar para a "Casa de Apoio" por ter ficado lá tempo demais, apesar das tentativas da equipe do CAPS ad de retomar essa negociação com a As Social. Também não conseguiu mais freqüentar o CAPS ad pois não aceitou as mudanças na equipe técnica e infelizmente a perda de algumas figuras de referência em seu processo terapêutico.

\section{Considerações finais:}

A proposta deste relato de experiência foi demonstrar como o acompanhamento e a intervenção do CAPS ad no caso de um sujeito morador de rua e com grave dependência de álcool nos ajuda a levantar diversas questões sobre os processos de trabalho desenvolvidos nos CAPS ad.

A construção do projeto terapêutico singular de P. levou em consideração o desejo e a possibilidade do encorajamento de P. a realizar. Assim, diante das demandas sociais ("trabalhe, produza") encontrar uma atitude possível contrária a isso, diferente de se colocar numa postura alienada e "fingir que não é comigo". Não ter responsabilidade (habilidade de resposta) é uma afronta ao sistema, ainda que para isso ele tenha que se destruir. O sujeito da banalidade (Muller-Granzotto\&Muller-Granzotto) sente-se impotente diante das coisas, impossibilitado de mudar o mundo e as pessoas, e principalmente a si mesmo.

A intervenção por parte do terapeuta quando esse ajustamento aparece no "campo" passa pelo encorajamento, ou seja, ajudamos o sujeito a identificar o desejo e o encorajamos a realizar. Ele assume assim um posicionamento frente aos seus excitamentos e 
também diante do Outro social. Dar visibilidade e voz a alguém que dizia fazer questão de "ser invisível", por sentir vergonha de sua situação de morador de rua e alcoolista. Identificar suas potencialidades e ajudar a fazer ele acreditar ser possível realizar. Exercitar suas potencialidades, dentro de um local protegido que é o CAPS ad, permitiu desenvolver em P. maior autoestima e confiança para resgatar seus projetos de vida fora da instituição. Para os técnicos de referência a questão de não demandar, de não esperar, de suportar as decepções e de ter de estar sempre recomeçando foi e é o grande desafio de trabalhar com a questão da dependência de álcool e outras drogas.

Outro desafio foi a construção da própria rede Inter setorial devido a instabilidade das propostas de acolhimento dos serviços, tanto na saúde quanto na As. Social devido à flutuação dos profissionais envolvidos no processo. Assim, acredito que a rede é construída por pessoas e passa pela formação e principalmente pelo desejo dessas pessoas a possibilidade de construção de parcerias na assistência e não por instituições ou normas.

O acesso da população moradora de rua nos serviços de saúde é uma questão crítica e que precisa ser pensada e articulada intersetorialmente, com diversas instâncias públicas como a Assistência Social, a Habitação e a Segurança Pública. Os CAPS ad como serviços de saúde mental, em geral se limitam a intervenções dentro da instituição e na grande maioria das vezes de forma coletiva e pedagógica esquecendo-se de olhar para singularidade de cada caso. Esse cuidado deve ser ampliado no caso do morador de rua, que precisa ser visto, como um sujeito em reconstrução em todos os aspectos: ético, político e social o que requer uma intervenção ampla e multisetorial.

No caso de P., buscamos trabalhar numa perspectiva integrada, estabelecendo uma comunicação com os serviços assistenciais, como a Casa de Apoio Social e a Assistência Social do Município. Foi importante estabelecer um vínculo institucional e espaços de negociação e discussão dos casos, já que o tempo das intervenções e do processo de cuidado muitas vezes não é o mesmo das demandas institucionais dos outros serviços. Evidenciamos na prática os problemas estruturais que atravessam os serviços, como a burocracia pública na tentativa de assegurar benefícios aos usuários e a rotatividade das equipes técnicas e, principalmente, o "fechar as portas" quando por ocasião de uma recaída.

A intervenção clínica deste caso possibilitou ainda importantes transformações interinstitucionais na própria equipe do CAPS ad. As diversas discussões nas reuniões de equipe levaram a quebra de alguns paradigmas, resquícios do modelo manicomial centralizador. A retomada de aspectos éticos da clínica psicossocial como a horizontalidade das relações, foi fundamental para o processo de construção das intervenções terapêuticas necessárias nesse caso.

Concluindo, destacamos o desfecho (até agora, já que está sempre em construção) do caso de P. no CAPS ad, que evidencia muito da realidade dos nossos serviços assistenciais. A rotatividade técnica nos serviços, os entraves burocráticos e as dificuldades na comunicação Inter setorial, que são aspectos constituintes da prática nos serviços públicos de saúde e de outras dimensões do poder público. O caso de P. ilustra estas dificuldades e também apresenta as potencialidades que precisam ser repensadas na questão da clínica com o dependente químico e morador de rua.

Esse compromisso de uma construção coletiva entre as esferas assistenciais é o que podemos planejar e aperfeiçoar em nossas ações com este público, enquanto profissionais da saúde. Dessa forma, a reabilitação não é simplesmente a passagem da desabilitação para a habilitação, mas "um conjunto de estratégias orientadas visando aumentar as oportunidades de troca de recursos e de afetos: é somente no interior de tal dinâmica das trocas quase cria um efeito "habilitador". Por meio dessas trocas materiais e afetivas se cria uma "rede de negociação", as quais aumentam a participação e o poder de contratualidade dos indivíduos menos favorecidos em uma sociedade.

\section{Referências:}

Brasil (2003). Ministério da Saúde. A Política do Ministério da Saúde para a Atenção Integral a Usuários de Álcool e Outras Drogas. Brasília, 2003.

Brasil (2008). Pesquisa Nacional sobre a População e Situação de Rua. Brasilia, 2008.

Carlini, E. A. II Levantamento domiciliar sobre uso de drogas no Brasil: estudo envolvendo as 108 maiores cidades do país 2005. São Paulo: Centro Brasileiro de Informações sobre Drogas Psicotrópicas, Departamento de Psicobiologia, Escola Paulista de Medicina; 2005.

Carneiro J. N.; Nogueira, E.;Lanferini, G. M.; Ali D. A.; Martinelli, M. Serviços de saúde e população de rua: Contribuição para um debate. Saúde e Sociedade, 7(2): 47-62, 1998.

Costa, A. P. M. População em situação de rua: contextualização e caracterização. Revista Virtual.Textos\& Contextos, n. 4, dez., 2005 .

Costa-Rosa, A., Luzio, C. A., Yasui, S. Atenção Psicossocial: rumo a um novo paradigma na Saúde Mental Coletiva. In: Amarante, P. Archivos de saúde mental e atenção psicossocial. Rio de Janeiro: NAU Editora, 2003.

Saraceno B. Reabilitação psicossocial: uma estratégia para a passagem do milênio. In: Pitta AM, organizadora.

Reabilitação psicossocial no Brasil. São Paulo (SP): Hucitec;1996. p.13-8.

Müller-Granzotto, Marcos José \& Rosane Lorena. Fenomenologia e Gestalt-terapia. São Paulo: Summus, 2007. 366p.

Müller-Granzotto, Marcos José \& Rosane Lorena. Clínicas Gestálticas. São Paulo: Summus, 2013

Organização Mundial da Saúde (OMS). Organização PanAmericana da Saúde (OPAS). Relatório sobre a saúde no mundo. Saúde Mental: nova concepção, nova esperança. Genebra; 2001.

Pimenta, C. A. M.; Silva, C. L. Moradores de rua e a realidade social contemporânea: subsídios para intervenção no município de Taubaté/SP. Revista Brasileira de Gestão e Desenvolvimento Regional, v. 6, n. 3, p. 136-158, set-dez., Taubaté/São Paulo, 2010. 
Varanda, W.; Adorno, R. C. F. Descartáveis urbanos: discutindo a complexidade da população de rua e o desafio para as políticas de saúde. Saúde \& Sociedade, v.13, n.1, p.56-69, jan-abr. 2004.

Vieira, M. A. C.; Bezerra, E. M. R.; Rosa, C. M. M. (orgs.). População de Rua: quem é, como vive, como é vista. 2. ed. São Paulo: Hucitec, 1994.

Feffermann, M.;Figueiredo,R. Redução de Danos como Estratégia de Prevenção de Drogas entre Jovens In: Boletim do Instituto de Saúde, no 40, dezembro de 2006. São Paulo, Instituto de Saúde - SES

Recebido: $30 / 08 / 2012$

Última revisão: 16/10/2013

Aceite final: 17/10/2013

Sobre os autores:

Célia Regina Pessanha Mendes - Médica psiquiatra pela UERJ, Pós graduação em gestalt-terapia pelo Instituto Muller-Granzotto. Trabalha no CAPS ad Ilha em Florianópolis SC.

E-mail: celiaremp@gmail.com; celiamds@outlook.com

João Fillipe Horr - Psicólogo pela UFSC, Mestrando em Psicologia pela UFSC.

E-mail: jf.horr@gmail.com 